\title{
A thermomechanical technology of borehole wall isolation using a thermoplastic composite material
}

\author{
Andrii Sudakov ${ }^{1, *}$, Andrii Dreus ${ }^{2}$, Yurii Kuzin ${ }^{1}$, Diana Sudakova ${ }^{1}$, Boranbay Ratov ${ }^{3}$, and \\ Oleh Khomenko ${ }^{1}$ \\ ${ }^{1}$ National Technical University Dnipro Polytechnic, 49005, Dnipro, Yavornytskoho Ave., 19, Ukraine \\ ${ }^{2}$ Oles Honchar Dnipro National University, 49010, Dnipro, Haharina Ave., 72, Ukraine \\ ${ }^{3}$ Satbayev Kazakh National Research Technical University, 050000, Almaty, Satbayev Str., 22a, \\ Kazakhstan
}

\begin{abstract}
Loss of drilling fluid in wells is one of the most important drilling challenges. To prevent this problem an insulation of borehole wall is requiring. The results of study of an innovative technology of isolation of borehole using a new thermomechanical plugging material are presented herein. The material considered is solid composite consisting secondary polyethylene terephthalate and gravel. Theoretically and experimentally shown the possibility to use this material to borehole isolation. The technology of manufacturing and isolation of absorbing horizons by thermomechanical material has been developed. Dependence of the regime parameters of the thermomechanical process melting of material on the thermophysical properties and technical characteristics was established. Dependence of the penetrating ability of material melt on the fractures was established. The results of work can be used to recommend technology parameters providing the efficient melting rate.
\end{abstract}

\section{Introduction}

Often drilling of exploration and production wells are being conducted in rocks with high degree of metamorphism and fractured $[1,2]$. The process of drilling wells is related with geological complications. Most frequent types of complications that violate the technology of drilling, is absorption drilling fluids. The annual cost of time in the total balance for drilling increased to $23 \%$ and costs up to $10 \%$. In most cases, the elimination of absorption is ensured by the isolation of borehole wall. Usually, to eliminate the absorption of flushing fluid used are cement solutions which are prepared on a water basis with the introduction the minerals or synthetic substances. There are some disadvantages of these methods. Properties cement mortar is changing at contact with borehole fluid because it is diluted. Due efficiency of isolation of the absorbing horizon is reduced, and repetition of cementing operate could be need. The various approaches to solution of this problem were considered in [3-6].

\footnotetext{
*Corresponding author: sudakovy@ukr.net
} 
A new thermomechanical technology of borehole wall isolation using a thermoplastic composite material was developed in National Technical University Dnipro Polytechnic [7]. The technology using the effect of changing the physicomechanical properties of the composite material under high temperature due to the operation of the thermomechanical tool. To ensure rational technological parameters, comprehensive studies were conducted. The results of investigation are presented below.

\section{Experimental results}

\subsection{The study physical and mechanical properties of thermoplastic composite material (TCM) on secondary polyethylene terephthalate (PET)}

PET is one of the most common household wastes. According to statistical data its volume makes up to $20-25 \%$ of the total mass of household waste.

As a result of the analysis of known physical and mechanical properties of PET installed the possibility of its use as a scanning TCM for the isolation of absorbing horizons drill holes $[8,9]$. Secondary PET:

- is not washed with water and can be used in a well regardless of groundwater velocity;

- chemically inert;

- does not change for a long time physical and mechanical properties. Complete decomposition PET is about 300 years old. Density of PET $1.38-1.45 \mathrm{~g} / \mathrm{cm}^{3}$, tensile strength $172 \mathrm{MPa}$, flexural strength 50 - $70 \mathrm{MPa}$, compressive strength 80-120 MPa;

- its cost is comparable to the cost of cement and much lower than the cost of such materials such as sulfur, bitumen, synthetic resins.

In the course of laboratory studies of physical and mechanical properties of TCM:

- the necessity of introducing the filler into its substantiation is substantiated. Secondary PET Cooling in forms, collapses due to the formation of radial deep cracks. In a break patterns of high-porosity structure. All samples are characterized by the phenomenon of shrinkage. Its size is not exceeded $25 \%$. On this basis, it was done conclusion on the impossibility of using secondary PET as an independent tampon the material Therefore, with the "clean" secondary PET work was stopped;

- the type and optimum concentration of the filler are determined;

- it was shown that TCM with a filler volume less than $0.5 \mathrm{~mm}$ in a ratio of $1: 1$;

- has the highest strength characteristics (fig. 1), and at the age of 15 minutes it is $52.6 \mathrm{MPa}$, which in 5.26 times higher than the strength of the prototype - a cementitious stone cement at age 7 days (fig. 2);

- in the range of temperatures $250-300{ }^{\circ} \mathrm{C}$ has a diffusion, which is comparable with the spreading normal cement mortar;

- permeability of the plugging stone with TCM for 24 hours at a pressure differential of $20 \mathrm{MPa}$ absent;

- is a "very abrasive" material, despite the highest degree of wear resistance.

Thus, as a plugging material, the use of TCM on a basis is recommended PET with granular filler with a grain size less than $0.5 \mathrm{~mm}$. Generalized physical and mechanical properties of TCM are given in table. 1 The technology of manufacturing TCM on the basis of PET, which consists of the preparatory stage, the stage of manufacturing the composite and the formation. 


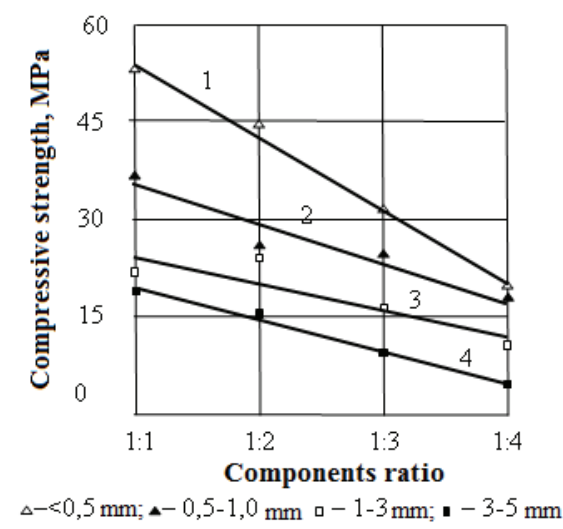

Fig. 1. Dependence of compressive strength on the grain size and components ratio.

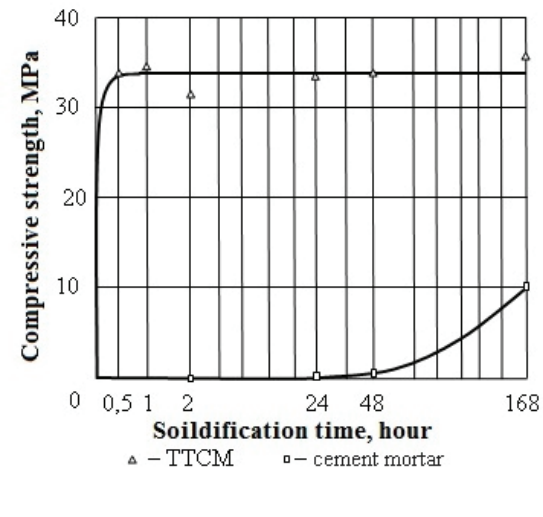

Fig. 2. Dependence of compressive strength on solidification time for TCM (components ratio is $1: 3$, grain size less than $0.5 \mathrm{~mm}$ ) and cement solution.

\subsection{Development of technology of isolation of absorbing horizons of drill holes with using TCM}

The method of isolation of absorbing horizons with application is developed and substantiated TCM on the basis of PET, for implementation of which it is necessary to perform such technological operations: transportation of TCM to the absorbent the horizon of the drill hole, the melting TCM in a drill hole and clamping TCM in the absorption channels. Substantiated technology of transportation of cylindrical bricks TCM along the wellbore and the possibility of thermomechanical contact melting of TCM in the absorption zone flushing fluid. The technical advantages of technology include:

- possibility to control the technological process of melting of TCM in the area of complication;

- the possibility of eliminating the freezing (jamming) of TCM during transportation on wellbore;

- absence of the operation to remove from the trunk of the technological tool, and at the expense of this reduction of time costs.

Technological modes of process of thermomechanical melting of tampon material

When tiling the permeable horizon with the use of TCM-based PET, they were determined methods of physical modeling in stand conditions.

For this purpose, the design and manufacture of: based on similarity criteria experimental stand, which allows you to simulate the processes occurring in absorbing horizon with different disclosure of flat radial cracks; laboratory thermomechanical tool, which allowed for thermomechanical Melting on a well hole to create a power from $1.7 \mathrm{~kW}$ to $5.8 \mathrm{~kW}$.

As a result of bench studies [8-10]:

- the possibility of thermomechanical melting on the well hole has been proved monolithic briquetted TCM;

- it is established that: thermomechanical speed of drilling (melting), regardless of the ratio of the filler to the filler, as well as the formulation of TCM to the regime parameters, and has one order of magnitude, which increases with the increase of the axial load and speed of rotation (fig. 3); time of heating TCM to its temperature melting depends on the 
formulation of TCM; at opening of a crack of 10 - $30 \mathrm{~mm}$ melt of TCM flows out from the trunk of the well from $20-30 \mathrm{~mm}$ to $80-90 \mathrm{~mm}$, forming a small volume impenetrable insulating shell around the well (fig. 3);

- the dependence of temperature change in TCM on the magnitude of the regime is established parameters. Place the figure as close as possible after the point where it is first referenced in the text. If there is a large number of figures and tables it might be necessary to place some before their text citation.

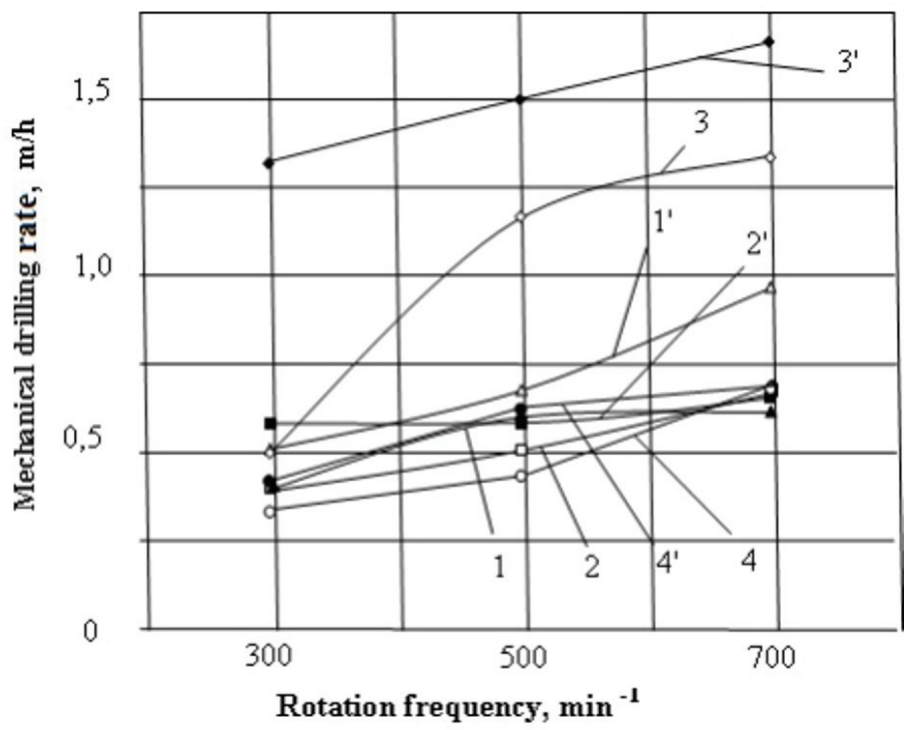

Fig. 3. Dependence of the thermomechanical drilling speed (melting) on the frequency of the rotation of the thermomechanical tool.

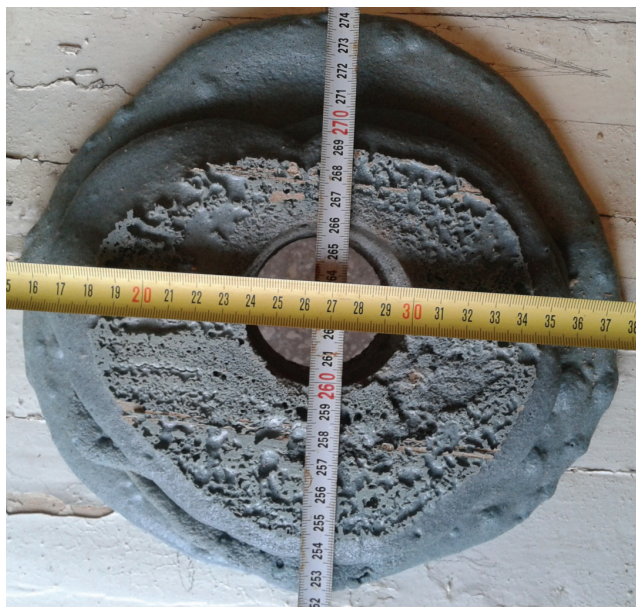

Fig. 4. Distribution radius of TCM in a crack with an opening of $30 \mathrm{~mm}$.

Proven experimentally and confirmed by analytical studies that: thermomechanical melting of TCM does not exceed its heating temperature the critical value at which the destruction occurs; the temperature increase in the sample TCM to the melting point occurs at the zone of contact of the working body of the instrument, with the front of its influence ahead of the end The surface of the instrument is $7-8 \mathrm{~mm}$. 


\section{Theoretical results}

In the course of theoretical studies the approaches to thermal physical simulation are considered melting to order determination velocity of drilling (penetration rate) production presented technology. From the solution of the heat transfer problem [7] was establishes the relationship between the regime parameters of the technological process and the parameters of the thermal physical processes during the operation of the tool

$$
F n=\frac{\lambda D}{2 \mu k_{m} \sqrt{\pi a \tau_{f}}}\left(t_{f}-t_{0}\right),
$$

where $\tau_{f}$ - time of heating the surface to the melting point; $t_{0}$ - initial temperature; $t_{f}$ - melting point of TCM, where $\lambda$ - heat conductivity coefficient, $a$ - heat diffusivity coefficient, $\mu$ - the coefficient of friction; $k_{m}$ - coefficient, which takes into account the proportion of heat of friction going on heating and melting TCM; $F$ - axial load; $D$ - the diameter of the surface of the friction; $n$ - the frequency of the tool rotation.

To determine the rate of penetration rate, the equation of thermal balance is used

$$
q_{\text {friction }}=q_{\text {melt }}+q_{\lambda}
$$

where $q_{\text {friction }}$ - friction heat flux, $q_{\text {melt }}$ - heat flax to melt the surface layer of a material of thickness $\mathrm{d} \xi$ during time $\mathrm{d} \tau ; q_{\lambda}-$ is the heat flow that goes on to warm up the inner layers of the material, which is determined according to the Fourier law. The heat flow $q_{\text {melt }}$ is described by the expression

$$
q_{m e l t}=\rho L \frac{\mathrm{d} \xi}{\mathrm{d} \tau},
$$

where $L-$ latent heat of melting of TCM; $\rho-$ TCM density. The rate of thermomechanical drilling is defined as $V=\mathrm{d} \xi / \mathrm{d} \tau$.

Thus, from equation (2), using the solution of the heat problem and (1), (3) the regime of drilling parameters, we obtain an expression for the rate of thermomechanical drilling

$$
V=\frac{1}{\rho L}\left(\frac{4 \mu k_{m} F n}{D}+\frac{\lambda\left(t_{f}-t_{0}\right)}{\sqrt{\pi a \tau}}\right) .
$$

Analyzing (4) for, we obtain a formula for the limit speed of thermomechanical drilling

$$
V_{\lim }=\frac{1}{\rho L}\left(\frac{4 \mu k_{m} F n}{D}\right) .
$$

The average speed of thermomechanical drilling in time $\mathrm{T}$ will be determined as

$$
V_{a v}=\frac{1}{\mathrm{~T}} \int_{0}^{\mathrm{T}} V(\tau) \mathrm{d} \tau,
$$

where $\mathrm{T}$ - drilling time; $V(\tau)$ - is determined by the expression (4).

After integrating (6) over time in the range from 0 to $\mathrm{T}$, taking into account the condition $\xi=0$ for $\tau=0$, we obtain the expression for the depth of drilling for the period $\mathrm{T}$ 


$$
h=\frac{1}{\rho L}\left(\frac{4 \mu k_{m} F n}{D} \mathrm{~T}+\frac{2 \lambda\left(t_{f}-t_{0}\right)}{\sqrt{\pi a}} \sqrt{\mathrm{T}}\right) .
$$

The results of the performed analysis of the calculation algorithm, as well as the calculated dependences of the change in the penetration and speed of the thermomechanical melting of the TCM in the borehole in time (Fig. 5), are presented in the form of a nomogram of the dependence of the regime parameters on the rate of thermomechanical melting of the TCM on the well hole. Thus, with an axial load of $700 \mathrm{daN}$ and a rotational speed of $700 \mathrm{~min}^{-1}$, the calculated thermomechanical melting speed of a tool with a diameter of $46 \mathrm{~mm}$ will be $-1.2 \mathrm{~m} / \mathrm{hr} ; 59 \mathrm{~mm}-1.0 \mathrm{~m} / \mathrm{hr} ; 76 \mathrm{~mm}-0.84 \mathrm{~m} / \mathrm{hr} ; 93 \mathrm{~mm}-$ $0.74 \mathrm{~m} / \mathrm{hr} ; 269 \mathrm{~mm}-0.46 \mathrm{~m} / \mathrm{hr}$.

The results of calculations in the generalized form, shown in fig. 6, are valid for a thermomechanical tool with a diameter of $59 \mathrm{~mm}$.

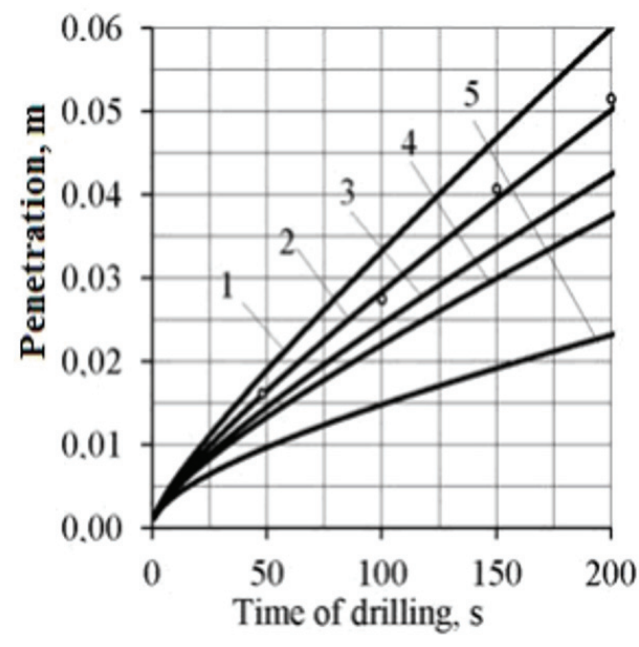

Fig. 5. Calculation dependence of the penetration on time and tool size, with an axial load of $700 \mathrm{daN}$ and a rotation speed of $700 \mathrm{~min}^{-1}: 1-46 \mathrm{~mm} ; 2-59$ $\mathrm{mm} ; 3-76 \mathrm{~mm} ; 4-93 \mathrm{~mm} ; 5-269 \mathrm{~mm} ; \mathrm{o}-$ experimental results.

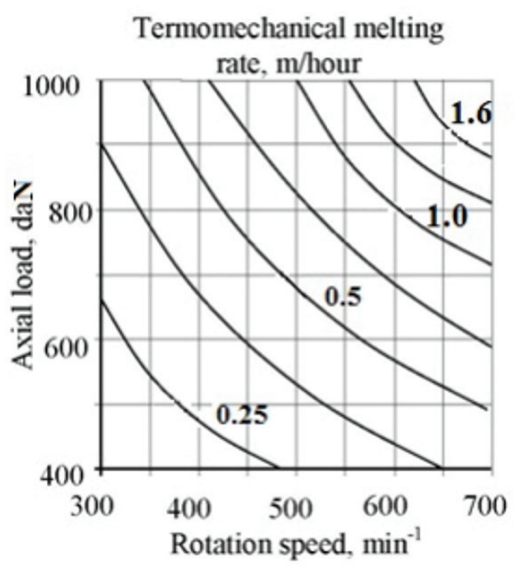

Fig. 6. The calculated dependence of the stationary thermomechanical melting rate of TCM on the value of the regime parameters.

Taking into account the results of researches of physical and mechanical properties of TCM, shown in section 2, as well as the results of bench and analytical studies thermomechanical parameters of the technology of drilling (melting) of TCM for use in well conditions recommended by TTCM with the ratio of components $1: 1$, combined with an axial load of at least $700 \mathrm{daN}$ at the speed of the tool $700 \mathrm{~min}^{-1}$.

\section{Conclusions}

1. The formulation has been developed and substantiated and the possibility of application is confirmed TTCM, the base of which are inert thermoplastic household waste based on secondary polyethylene terephthalate with a granular filler of less than $0.5 \mathrm{~mm}$ thick, in a ratio of 1:1, providing: at the age of 15 minutes, the strength properties are 5.26 times higher than strength of a trowel stone on a cement basis at the age of 7 days; in the range of temperatures $250-300{ }^{\circ} \mathrm{C}$ dispersion compared with the spread of a normal cement mortar; 
absence of tangential stone permeability at a pressure differential of $20 \mathrm{MPa}$; the highest degree wear resistance, is a "very abrasive" material.

3. The theoretically and experimentally shown the possibility of making briquettes TTCM The technology of manufacturing TTCM on the basis of PET, which consists of the preparatory stage, the stage of manufacture and formation. Rationalized rational technological modes of manufacturing TTCM.

4. The technology of isolation of absorbing horizons from. Is developed and substantiated application of TTCM on the basis of PET, for realization of which it is necessary to perform the following technological operations: transportation of cylindrical briquettes of TTCM by 1-15 mm less the diameter of the rock-cutting tool to the absorbing horizon of the drill hole, thermomechanical melting of TTCM at a temperature of $246{ }^{\circ} \mathrm{C}$ in the absorption zone of the drill well and compression of superheated TTCM with a melt temperature of $280-300{ }^{\circ} \mathrm{C}$ in absorption channels.

5. In the course of experimental and theoretical research justified rational technological modes of borehole thermomechanical melting of TTCM based on PET. The developed TTCM is recommended to be used in well conditions, in conjunction with the axial load is not less than $700 \mathrm{daN}$ at the speed of the tool $700 \mathrm{~min}^{-1}$.

\section{References}

1. Y. Feng, J. F. Jones, K. E. Gray, SPE Drilling \& Completion, 31, 02, 134-144 (2016)

2. B. Aadnoy, R. Looyeh, Petroleum rock mechanics: drilling operations and well design. (Gulf Professional Publishing, 2011)

3. M. Khalifeh, H. Hodne, A. Saasen, O. Integrity, E. I. Eduok, SPE Asia Pacific Oil \& Gas Conf. and Exhib. Soc. of Petrol. Eng., SPE-182354-MS (2016, October)

4. Y. Liu, T. Song, Y. Xu, Nat. Gas Ind., 3, 2, 158-164 (2016)

5. A.K. Sudakov, A.Yu. Dreus, O.Ye. Khomenko, D.A. Sudakova, Nauk. Visnyk Natsion. Hirn. Univ., 3, 159, 32-46 (2017)

6. H. Yu, L. Li, J. Zheng, W. Ji, X. Qin, X. Fu, W. Gao, SPE Latin America and Caribbean Heavy and Extra Heavy Oil Conference, SPE-181173-MS (2016)

7. A. Sudakov, A. Dreus, D. Sudakova, O. Khamininch, E3S Web of Conf. 60 (2018)

8. J. Kuzin, O. Mostinets, D. Sudakova, M.Isakova, Nauk. Visnyk Natsion. Hirn. Univ., 1, 157, 34-39 (2017)

9. Yu. Kuzin, D. A. Sudakova, M. V. Lukyanenko, Mining Forum - 2017:Iinternational scientific and technical conference, 242-247 (Dnepr, October 2017).

10. A. Sudakov, A. Dreus, B. Ratov, D. Delikesheva, News of the Nation. Acad. of Scien. of the Repub. of Kazakhstan, 2, 428, 72-80 (2018) 